\title{
Acción colectiva, antagonismos y resistencia comunitaria en el conflicto socio-territorial de Freirina
}

\author{
Collective action, antagonisms and community resistance in the \\ socioterritorial conflict of Freirina
}

\author{
Cory Duarte-Hidalgo* \\ Carolina López-Rojas** \\ Paloma Ochoa-García*** \\ Paula SalazAr-EnríQuez ${ }^{* * * *}$
}

\section{Resumen}

Objetivo. Analizar la acción colectiva desarrollada en el marco del conflicto socio-territorial en la localidad de Freirina, Atacama, Chile. La Asamblea Freirina articuló una resistencia comunitaria como respuesta al funcionamiento de una planta faenadora y procesadora de cerdos, lo que implicaba una serie de consecuencias para el territorio y la comunidad. Metodología. El estudio, de tipo cualitativo con alcance descriptivo-interpretativo, recoge mediante entrevistas focalizadas los relatos de integrantes de la Asamblea respecto a sus reflexiones y análisis sobre el conflicto. Resultados. Se observa una organización comunitaria que desplegó distintos repertorios de acción, la existencia de relaciones antagónicas suscitadas en el conflicto, la importancia de los espacios y territorios locales, y la resistencia comunitaria en la lucha por la dignidad. Conclusiones. El análisis del conflicto socio-territorial permite evidenciar las tensiones entre capital y naturaleza, y la fuerza de la organización comunitaria como actor político relevante en la defensa del territorio.

Palabras clave: acción colectiva, conflicto socioterritorial, relaciones antagónicas, resistencia comunitaria.

\begin{abstract}
Objective: To analyze the collective action developed within the framework of the socioterritorial conflict in the town of Freirina, Atacama, Chile. The Freirina Assembly articulated a community resistance in response to the operation of a slaughterhouse and pig processing plant, which implied a series of consequences for the territory and the community. Methodology: The study, of qualitative type with descriptive-interpretative scope, collects the stories of members of the assembly
\end{abstract}

\footnotetext{
*Universidad de Atacama. Copiapó, Chile. E-mail: cory.duarte@uda.cl

(D) orcid.org/0000-0002-1532-3123 Google Scholar

** Universidad de Atacama. Copiapó, Chile. E.mail: c.lopezrojas25@gmail.com

(D) orcid.org/0000-0001-9924-5240 Google Scholar

**** SENDA Previene, Caldera. Copiapó, Chile. E-mail: palomafog@gmail.com

(D) orcid.org/0000-0003-4069-4812 Google Scholar

***** Universidad de de Atacama. Copiapó, Chile. E-mail: paulasalazar22@gmail.com

(D) orcid.org/0000-0002-6295-5318 Google Scholar
} 
regarding their reflections and analysis of the conflict through focused interviews. Results: A community organization that displayed different repertoires of action, the existence of antagonistic relationships raised in the conflict, the importance of local spaces and territories, and community resistance in the struggle for dignity are observed. Conclusions: The analysis of the socio-territorial conflict allows demonstrating the tensions between capital and nature, and the strength of community organizations as relevant political actors in the defense of the territory.

Key words: collective action, socio-territorial conflict, meanings, antagonistic relations, community resistance

\section{Introducción}

En los últimos años, la región de Atacama, ubicada en el desierto del mismo nombre en el extremo norte de Chile, ha vivenciado conflictos entre actores territoriales y empresas de capitales trasnacionales, lo que generó una serie de resistencias locales (García, 2012; Astudillo, 2015; Mora, Duarte y Rodríguez, 2017; García, 2017). La lógica extractivista ha sido la tónica en este tipo de situaciones, intensificándose una acción depredadora en regiones productoras de recursos naturales, de forma que, la inequidad y la acumulación por desposesión se transforman en sellos característicos del territorio, en una clara muestra de nuevas territorialidades extractivistas que se asientan en Latinoamérica (Jeréz, 2015). Localidades como Huasco, Totoral y Chañaral han sido sitio de este tipo de conflictos socioterritoriales en la región, con historias y memorias distintivas respecto de las formas en que las disputas por el territorio y sus corporalidades se han establecido.

Haesbert (2011) señala la importancia de considerar en la noción de territorio no solo los aspectos geográficos-espaciales sino también la confluencia de aspectos materiales y simbólicos, en una diada que involucra las ideas de dominio y apropiación de los espacios. Esta dualidad hace que los territorios contengan una mirada multifocal dada su diversidad, riqueza y complejidad; mirada que se contrapone a la lógica capitalista hegemónica que les considera bajo una sola perspectiva. De esta forma, los conflictos socioterritoriales se caracterizan por la confluencia de visiones distintas sobre el espacio y las formas de control de sus recursos. Lo anterior genera tensiones en el espacio local vivido, debido a las disparidades en las lógicas y marcos en que dichos espacios se estipulan.

La investigación presentada analiza el conflicto socioterritorial acaecido en la localidad de Freirina. Esta se sitúa en el desierto más árido del mundo, en una región de profunda historia minera, con una notable presencia de proyectos abocados a esta rama de extracción. En los valles que cruzan el paisaje desierto es posible encontrar empresas relacionadas con la agroindustria, las que a partir de la década del setenta del siglo pasado aportan tecnología 
Acción colectiva, antagonismos y resistencia comunitaria en el conflicto socio-territorial de Freirina

agrícola a los tradicionales cultivos de olivos y otros frutales (Rodríguez, Duarte y Mora, 2015); asimismo, existe un considerable número de proyectos productores de energía asociados a la instalación de energía fotovoltaica, eólica y termoeléctrica. Estos proyectos coexisten con formas tradicionales de cultivo agrario, formas artesanales de extracción minera, turismo y otras actividades de servicios.

La región de Atacama, y particularmente el Valle del Huasco, se ha configurado como una zona de sacrificio (García, 2012; Vargas, 2014), en la que existe una condensación de industrias altamente contaminantes. En ella encontramos al menos 15 conflictos socioambientales activos (Instituto Nacional de Derechos Humanos, 2015). Lo anterior, expone a la población a una gran contaminación, generando afecciones a la salud de las personas y una considerable disminución en su calidad de vida (Duarte y García, 2013). Asimismo, la instalación de megaproyectos no ha significado impactos positivos para la región, más bien se ha degradado el territorio, marcándolo como una zona desamparada de la protección estatal en torno a la garantía constitucional del derecho a vivir en un medioambiente libre de contaminación.

La investigación aquí presentada analiza la acción colectiva en el conflicto socioterritorial acaecido en la comuna de Freirina, en el marco de la implementación y posterior retirada del Proyecto Agropecuario Valle del Huasco. Lo anterior, implicó considerar el relato de los y las participantes de la Asamblea Freirina, asumiendo la comprensión del contexto, las relaciones antagónicas entre los actores involucrados en el conflicto socioterritorial y los significados que los y las participantes de Asamblea Freirina atribuían a la acción colectiva que responde al conflicto socio territorial.

\section{Elementos contextuales}

El proceso investigativo se desarrolló en la región de Atacama, específicamente en la provincia del Huasco, comuna de Freirina, en la cual se desarrolló, en 2012, un levantamiento social en contra del Proyecto Agroindustrial Valle del Huasco de la empresa Agrosuper.

Freirina es una comuna de 7.041 habitantes según el censo del 2017, ubicados en una extensión global de $3280 \mathrm{~km}^{2}$. Esta comuna se encuentra ubicada a $176,2 \mathrm{~km}$ de la capital regional Copiapó, y a $36 \mathrm{~km}$ de la capital provincial, Vallenar. Su clima es desértico, distinguiéndose por la carencia casi absoluta de precipitaciones, fuerte amplitud térmica, bajo nivel de humedad y una gran limpidez atmosférica con cielos de escasas nubes.

En el momento en que la empresa Agrosuper evalúa instalarse en dicha comuna, la región de Atacama era la de menor crecimiento del país, y su pobreza alcanzó un 24,3\% en 2003, según datos de la Encuesta de Caracterización Socioeconómica Nacional (Casen). De igual manera, durante el primer trimestre del 2005, Atacama tenía una tasa de desempleo de 9,9\%, 
afectando de manera particular a la comuna de Freirina. En 2012, en el último trimestre, el desempleo era de 6,8\%.

Durante 2012, en el ámbito nacional, el gobierno impulsaba una agenda neoliberal orientada a la continuidad de la llamada gobernanza de los recursos naturales (Bolados, 2016), la que era confrontada con una cadena de movilizaciones sociales: multitudinarias manifestaciones estudiantiles, el conflicto en Aysén y una serie de demandas socioambientales que en ese periodo se desarrollaban (Astudillo, 2015).

En el marco del caso que aquí se expone, este se inicia en 2005 con la tramitación del Estudio de Impacto Ambiental para la aprobación del proyecto Agroindustrial Valle del Huasco. El día 7 se diciembre, la Comisión Regional de Medio Ambiente de Atacama aprueba el proyecto, pero con alcances. El complejo que albergaría a 150 mil cerdos comenzó funciones en 2007.

En enero de 2010 comenzó el funcionamiento de la planta de Agrosuper, con machos reproductores y chanchillas de 150 días, a pesar de que había construcciones pendientes como la planta faenadora y la de rendering. 11 meses después, se genera la primera denuncia por malos olores, la que fue dirigida a la Junta Nacional de Jardines Infantiles. En 2011 se realizan denuncias ante organismos medio ambientales regionales, lo que obligó la presencia de las autoridades. En marzo de 2012, Agrosuper notifica oficialmente a la autoridad medio ambiental del problema con los purines (aireación de los bio-corredores), situación que genera un escenario de incertidumbre y descontento, activando la movilización medio ambientalista del Valle del Huasco.

En el mismo año se crea la agrupación Freirina Consciente, la que posteriormente sería conocida como Asamblea Freirina. Esta organización formada por jóvenes que residían en la comuna y pobladores de años en el territorio se estructura a través de asambleas, las que alcanzaron gran magnitud.

El levantamiento social detona el día 21 de abril del 2012, con la ocupación de la carretera C-46, camino que une Vallenar con el puerto de Huasco, y el camino El Pino, vía que une Freirina con Huasco. Estas vías de acceso fueron sitiadas por la propia comunidad, la que organizó cuadrillas que instalaron barricadas para impedir el paso de cualquier vehículo hacia la planta de Agrosuper. En ese momento, la autoridad regional recibió un petitorio elaborado por la organización "Freirina Consciente", en el cual no solo se pedía la salida de Agrosuper del territorio, sino también la retirada de una serie de otros proyectos, así como acciones de protección de las tierras y las comunidades. En mayo la zona fue visitada por el Ministro de Salud, decretando alerta sanitaria por la masiva muerte de animales, estableciendo el cierre temporal de la planta e informando el traslado de los cerdos a plantas de la misma empresa en otras regiones. En diciembre de 2012 se produjo una reapertura de la planta, pero, tras las movilizaciones de la comunidad, la empresa decide cerrar de forma indefinida. 
Acción colectiva, antagonismos y resistencia comunitaria en el conflicto socio-territorial de Freirina

\section{Acciones colectivas y resistencias comunitarias}

A partir de mediados de la década del 2000, se observa una rearticulación de la acción colectiva en Chile (Durán-Migliardi, 2016). En este sentido, la idea de acción colectiva resurge como categoría analítica para comprender las formas en que los movimientos sociales se organizan y articulan. La acción colectiva ha sido teorizada y asociada a distintas miradas, pasando desde la teoría de la movilización de recursos, la discusión sobre las identidades, redes y oportunidades políticas (Tilly, 1978), enfoques cognitivos (Eyerman \& Jamison, 1991), el accionalismo (Touraine, 1984; Melucci, 1999) y otros elementos, derivando poco a poco hacia los estudios culturales (Jasper, 2012).

Existen elementos puntuales que son importantes para la comprensión de la idea de acción colectiva, entre ellos el que es siempre una tensión, un conflicto social, una disrupción al sistema social, una forma organizada de incomodar (que no siempre se define como un movimiento social), en la que se encuentran como principales subcategorías las nociones de solidaridad, identidad colectiva y redes (Melucci, 1999).

En los contextos situados en los que esta investigación se plantea, no es posible avanzar sin volver la mirada hacia las formas de sentir y hacer comunidad. Comunidad y acción colectiva son parte de un mismo relato, en el que la vivencia misma de estar en comunidad tiene un sentido que alude a lo colectivo. Maffesoli (2012) nos señala que la conciencia de sí da paso al sentido de pertenencia, elementos que ponen "el acento en las emociones compartidas y el placer/deseo de ser/estar juntos para ser/estar-juntos” (p. 115). Esta mirada de la acción, de lo comunitario, de los macro actores, nos permite hacer emerger elementos que no siempre están presentes en los análisis de las acciones colectivas y que consideran el conocimiento situado, los cuerpos, los afectos, el sentir, el placer, los miedos, la emociones (Jasper, 2012), una mirada relacional que se resumen en la premisa de Maffesoli (2012): el ser/estar juntos, pero que a la vez es una provocación a revalorizar lo territorial, pues el lugar es el que permite los vínculos y las interacciones en el espacio. En este sentido, la acción colectiva que desarrollan las comunidades es un proceso orientado a la acción inmediata, a "la realización in actu de la pulsión por estar-juntos" (Maffesoli, 1990, p. 45).

El ser/estar juntos, en el caso de estudio, genera una acción colectiva de corte comunitario y contenciosa. Esto último dado que el sentido de la acción se asocia a que la lucha tiene un marco asociado al ejercicio y exigibilidad de derechos (Peña, 2014), y que, "es utilizada por gente que carece de acceso regular a las instituciones, que actúa en nombre de reivindicaciones nuevas o no aceptadas y que se conduce de un modo que constituye una amenaza fundamental para otros o las autoridades" (Tarrow, 2004, p. 24). Al mismo tiempo, la acción colectiva se plantea como un proceso que tensiona las visiones que se tienen sobre el espacio y la territorialización de intereses económicos, sociales y políticos, pues el conflicto tiene relación con el giro ecoterritorial 
enunciado por Maristella Svampa (2011), en el cual el conflicto territorial es también un conflicto de características ambientales. Es decir, la acción y sus actuantes están asociados a la exigencia de derechos relacionados a la defensa del territorio, pero también a la defensa al derecho a vivir en un medio ambiente libre de contaminación, la autonomía de las comunidades sobre sus territorios y la participación de las comunidades en la toma de decisiones (Peña, 2014; Bolados, 2016), lo que conlleva una crítica férrea a las formas de ejercicio del poder. De ahí que se puedan identificar una acción colectiva de carácter contenciosa en la que se distinguen sujetos politizados, colectivos politizados y procesos políticos en las posiciones antagónicas inmersas en el conflicto (Peña, 2014), en el que la idea de redes es entendida como soporte a la acción, la cual tiene cierta regularidad en pos de generar objetivos comunes, identidades colectivas y forjar el estar-juntos. Estos elementos de orden político se generan como una "crítica a la irracionalidad del modelo neoliberal impuesto en Chile y una propuesta de una nueva racionalidad eco-socioambiental” (Bolados, 2016, p. 108).

En este sentido, la acción estatal permite la reorganización territorial al servicio del capitalismo, lo que necesariamente conlleva la fragmentación de la población (Guerra y Skewes, 2010) y la acumulación por desposesión (Harvey, 2004). Todo ello genera procesos en los que territorios que son despojados de su valor patrimonial, social, cultural, para ser resignificados como territorios en los que se espera o aceptan sacrificios "locales" como necesarios para el bienestar "general" (Gudynas, 2011, p. 388). Zonas de sacrificio, como bien lo saben quienes habitan el Valle del Huasco.

Lo anterior nos permite resituar la idea de resistencia comunitaria la cual está asociada a las estrategias y posicionamientos frente al poder que oprimen a las comunidades, en este estarjuntos y sus capacidades de vivenciar procesos y de generar formas de resistencias cotidianas, una resistencia que está orientada a la defensa de lo común (Laval y Dardot, 2012), y a la apropiación del espacio (Bourdieu, 1999), y que está encaminada hacia prácticas y discursos que son colectivos y políticos, lo que implica un ejercicio sentipensante por parte de las comunidades, en el que cuerpos, tierra, memorias y sentires, se conjugan en acción, práctica y discurso.

\section{Acciones colectivas en conflictos socioterritoriales latinoamericanos}

Las últimas décadas han estado marcadas por la emergencia de distintos conflictos de carácter socioterritorial en el cono sur andino de nuestra región. En los conflictos socio territoriales de la región se aprecian nuevos actores políticos y nuevas formas de hacer política "en distintos lugares (no urbanos, periféricos), mayoritariamente distantes de los actores tradicionales de la política (partidos y organizaciones formales) y a través de procesos de organización y 
Acción colectiva, antagonismos y resistencia comunitaria en el conflicto socio-territorial de Freirina

movilización diversos y heterogéneos”(Delamaza, 2019, p. 142). Este tipo de conflictos develan la relación conflictiva entre capital y naturaleza (Reyes y Rodríguez, 2015), pues son las formas de apropiación de esta última, y la incorporación de los territorios a las lógicas extractivistas, las que generan narrativas y prácticas incompatibles entre los intereses que se mueven en los distintos espacios y sus conceptualizaciones. De esta forma, en su mayoría, los conflictos socioterritoriales latinoamericanos tienen un carácter local, engarzado al territorio, lo que más tarde varía debido a la politización del conflicto y a una multiescalaridad, y en los que emergen redes asimétricas de actores (Delamaza, 2019), reconociéndose relaciones antagónicas, en muchas ocasiones, entre Estado, empresas y organizaciones sociales territoriales. Asimismo, se producen tensiones en tres aspectos: gobernanza formal, resistencias de las comunidades y el desarrollo del capital (Bebbington, 2007), en contextos que son locales y globales a la vez. Los conflictos socioterritoriales implican no solo el control de los recursos naturales y la gestión de los territorios, sino también, la sostenibilidad de la vida, las relaciones sociales, y las acciones comunitarias. En dicho marco, se observan una serie de conflictos etnoterritoriales, socioambientales, en los que se han desarrollado acciones colectivas de resistencia como respuesta al despojo, enmarcadas en el derecho a decidir con autonomía sobre los propios territorios y vidas. El desarrollo de acciones colectivas contenciosas surge como respuesta rebelde de sujetos subalternizados que se enfrentan al despojo de lo privado apoyado desde la institucionalidad pública. Así, se identifican una serie de conflictos debido a la explotación de recursos naturales, asociados a un modelo de desarrollo de corte neoextractivista, que atenta con las prácticas comunitarias y territoriales de la región, pero que a la vez implicar nuevos y complejos desafíos, tomando en cuenta la revitalización de la idea de la tierra y los territorios en América Latina.

En este sentido, en la región sur andina se identifican conflictos socio-territoriales como el caso de Arica, Chile, en el que articula una acción colectiva para tener una respuesta pública sanitaria por la contaminación por polimetales (Arriagada, 2012); el caso de HidroAysén en la Patagonia chilena, en la que se organiza una acción colectiva sin precedentes que instala idea de Patagonia sin represas (Reyes y Rodríguez, 2015); o el caso deTambogrande en Perú, en el que se articula una acción colectiva en oposición a la faena minera en un valle agrícola, la que movilizó a diversos actores sociales (Arce, 2015). En los tres casos mencionados, se puede observar una acción colectiva que se constituye en el conflicto, con actores no institucionalizados que se organizan y establecen sus repertorios a partir del conflicto, en lo que implica una coalición de actores más que movimientos sociales (Delamaza, 2019). El último punto es interesante, pues, los conflictos socioterritoriales implican consecuencias políticas derivadas, en los que se reconocen cambios en las relaciones entre actores, en la lógica de poder y creación de una nueva institucionalidad, los que a su vez, pueden generar una serie de consecuencias que van más allá de los territorios. 


\section{Metodología}

El estudio se realizó bajo el paradigma interpretativo-comprensivo, desde el enfoque cualitativo, utilizando para ello el estudio de caso, optando por un diseño de tipo interpretativo. Respecto de las técnicas de recolección de la información, se usaron entrevistas focalizadas. En relación con la muestra, se utilizó una homogénea y otra en cadena. En la muestra homogénea se consideró a personas residentes en la localidad de Freirina, participantes activos en la agrupación "Freirina Consiente”, actual “Asamblea Freirina”. Por otra parte, en la muestra en cadena, se identificaron participantes claves y se agregaron a la muestra. Respecto a los criterios de inclusión, se determinó que los y las entrevistados deberían ser mayores de 18 años, participantes dentro del periodo de algidez del conflicto (2011-2012) y que fueran residentes de la comunidad de Freirina (20 años o más). Estos criterios son seleccionados para dar una validez y coherencia en el alcance de los objetivos y, a la vez, realzar los relatos de quienes vivieron activamente la organización de la acción colectiva y el conflicto con la empresa, relevando el discurso de los y las participantes. Las entrevistas fueron grabadas, previa lectura y firma del consentimiento informado correspondiente. Se utilizó como apoyo el programa de análisis cualitativo ATLAS.ti. El proceso de análisis se realizó mediante el análisis de discurso.

Cabe destacar que, finalizado el proceso de investigación, se realizó una devolución con la comunidad participante, la que compartió y profundizó en algunos de los elementos que este artículo expone.

\section{Resultados}

El conflicto que detona la acción colectiva y la resistencia comunitaria no es la instalación de la empresa, sino el malestar y degradación de la calidad de vida de quienes habitan Freirina producto de la emanación de olores desde la planta. La falta de respuestas por parte de las autoridades genera el deseo de estar-juntos, la articulación de la acción colectiva y, posteriormente, la radicalización de los repertorios de acción. No obstante, la motivación varía durante el desarrollo de la acción. La escasez del recurso hídrico y la utilización de este por parte de la empresa fue un tema que poco a poco tomó peso. Se debe recordar que el Valle del Huasco ha estado marcado por movilizaciones sociales en defensa del agua y el territorio, por lo que la reflexividad de la asamblea respecto de este factor común con las luchas del Valle, hace que cambie la finalidad del movimiento. Si bien inicialmente estaba centrado en la defensa de un territorio específico, la demanda tempranamente se convierte en una nueva afrenta al Valle, un nuevo despojo en la utilización de sus recursos, lo que deriva en una demanda por la autonomía, en la exigencia de nuevas formas de ejercicio ciudadano y democrático. En este sentido, la acción colectiva se desarrolla en un ambiente en el cual confluyen diversos elementos, como las oportunidades políticas, pero también el desafío común, aquel que les 
Acción colectiva, antagonismos y resistencia comunitaria en el conflicto socio-territorial de Freirina

hermana con otras luchas, aquello que les hace asumir identidades múltiples y reconocerse como parte de un nosotros situado en Freirina, pero en conexión con las redes y acciones que se desarrollaban en otras localidades.

La creación de vínculos comunitarios permite la formación de un nosotros colectivo, el cual genera un sentido de pertenencia a un espacio, en función de un conjunto de valores y creencias que dan forma a ese sentir colectivo. El espacio, vivido, sentido, apropiado, vinculado, al ser usurpado propicia una articulación orientada hacia la defensa de la dignidad.

[...] estábamos siendo atropellados como seres humanos, no teníamos ni una dignidad, o sea aquí [...] aquí dijeron, nos dijeron a nosotros: o chanchos o gente [...]. (Entrevista 4, comunicación personal, 19 de noviembre de 2016)

La Asamblea decide trabajar para que Agrosuper se retire de Freirina. La finalidad de la movilización se vuelve una demanda que tiene relación con la autonomía de la comunidad para resolver sobre su territorio. Así, Asamblea Freirina debió utilizar toda su capacidad organizativa, informativa y combativa, para poder hacer palpable su fin. En ello, su principal fortaleza fue la conciencia adquirida, el grado de reflexividad sobre el conflicto, y la toma de decisiones en conjunto. De esta forma, la acción colectiva perduró aún después de la decisión de paralización de la empresa, pues la organización se propone una lucha contra el extractivismo y las formas en que este afecta a la comunidad.

La asamblea incorpora una disciplina y rigurosidad en su accionar. Estudian los fallos, las resoluciones, se instruyen respecto del conflicto. La existencia de liderazgos jóvenes que interpelan y hacen reflexionar sobre lo que estaba ocurriendo moviliza a la Asamblea, pues se nutren de las discusiones y los repertorios de acción que despliegan. La asamblea se convierte en un sujeto político colectivo que toma decisiones y genera un actuar organizado. Generan aprendizajes colectivos y toman decisiones en conjunto, por ejemplo, acuerdan el no negociar fuera del territorio, pues el conflicto no está disociado de las personas que lo habitan.
(...) entonces que si nosotros salíamos del territorio estábamos perdidos, los primeros aprendizajes que teníamos es que si íbamos a conversar alguna vez se hacía acá, acá, porque eso nos entregaba hegemonía, porque estábamos acá pos, estaba nuestra gente, por lo tanto ni siquiera a Vallenar fuimos a conversar. (Entrevista 1, comunicación personal, 26 de octubre de 2016)

Durante el conflicto, la Asamblea discutía y entablaba relaciones con redes. Importante fue la vinculación que tuvieron con la Mesa del Agua del Valle del Huasco, así como con las 
comunicaciones en las movilizaciones de Aysén y Caimanes. Se desarrolla una lógica organizativa distintiva, asentada en su experiencia organizativa y política, formas de articulación que permiten focalizar los niveles de incidencia y participación que requerían.

La propia Asamblea se dividía en tres grandes círculos. El primer círculo era la gente que iba a la Asamblea, la gente que participaba de discusiones de semana a semana o dos veces a la semana. Teníamos que juntarnos y no toda la gente va. El siguiente círculo era la gente que se comunicaba con la Asamblea, como preguntando, oye ¿y qué pasó en la Asamblea? (..) Y estaba un tercer círculo eh, en donde no le importaba lo que se discutía en Asamblea, ellos ya tenían tomada su decisión y estaban listos para actuar. (Entrevista 1, comunicación personal, 26 de octubre de 2016)

La acción colectiva desarrollada se articuló mediante la Asamblea la cual lideraba el proceso de resistencia y acción comunitaria desplegadas en la localidad.

\section{Relaciones antagónicas}

La acción colectiva se construye con base en relaciones antagónicas, emanadas del conflicto mismo, en las que permanentemente se desafía a los oponentes a tomar posición, y en la cual la ciudadanía organizada desafía a autoridades y antagonistas. En los relatos es innegable la crítica que hacen los y las entrevistadas a los intentos de mitigación y negociación que hiciera la empresa. El establecimiento de mecanismos de compensación y asistencias económicas se instala como forma de llegar a acuerdos, en concordancia con las características neoextractivistas (Gudynas, 2011) que tiene el conflicto. De esta forma, los y las pobladoras tienen la sensación de compra, el establecimiento de una relación mercantil con la empresa.

Cuando empezó Agrosuper aquí no salían de los \$180.000 la gente, pero cuando ya se generó esta cuestión del movimiento empezaron a aumentar, a generar conflicto. Ellos le subieron el sueldo a la gente ¿para qué? Para ganársela. Empezaron con las cositas de los regalos. Que un techito, que una casita pa' la señora que ponga una florería. Que pasaban niñas aquí, eran unas niñas encantadoras [...]Y se sentaban, ¿señor usted que es lo que necesita?

Para comprarlo...

Comprar nuestra conciencia. (Entrevista 4, comunicación personal, 19 de noviembre de 2016) 
Acción colectiva, antagonismos y resistencia comunitaria en el conflicto socio-territorial de Freirina

La empresa intenta generar quiebres en la organización, presiona comunicacionalmente, pero también amedrenta y usa la fuerza. Contrata guardias para la defensa de la tierra que han comprado, paramilitares le llaman los pobladores, consigue que fuerzas especiales de carabineros se instalen para proteger los terrenos de la industria. Los pobladores y pobladoras se sienten desprotegidas, perciben un manejo del conflicto desde fuera, en el cual las élites deciden y accionan en desmedro de la ciudadanía. En este sentido, los actores se definen y se declaran en oposición a todo quien se pusiera de lado de la empresa.

Uno de los aspectos más relevantes de este conflicto es el enfrentamiento con carabineros, el cual dotó a la acción de la construcción de un nosotros que se levantó para enfrentar a los oponentes. Conscientes de la asimetría de fuerzas y poder, resisten desde lo afectivo, pues es la defensa de la memoria, la tierra y la comunidad la que estaba en juego. La represión permitió la radicalización, pero también una mayor y mejor organización de la acción. La lectura del contexto y la oportunidad política hace que la comunidad pueda organizarse en la denuncia de las irregularidades y en la articulación de la resistencia. Carabineros se instalan en dependencias de la empresa para proteger la propiedad privada, lo que motiva aún más el enojo de los pobladores y pobladoras.

Las patrullas policiales, las micros de carabineros, estaban dentro de la empresa ¿cachai? [sic] O sea, ellos no estaban trabajando para la comunidad, ellos estaban trabajando para el poder empresarial derechamente. (Entrevista 7, comunicación personal, 24 de octubre de 2016)

Los pobladores y pobladoras acusan a carabineros de malos tratos y atropellos, tal y como queda evidenciado en las visitas que realizan organismos de derechos humanos.

Cuando fuimos [por] nuestros compañeros, te juro, fue una cuestión que me partió el alma. Ver a un chico que, carabineros de fuerzas especiales, le metieron, que lo golpearon, entero machucao; a la xxx le hicieron sonar sus pechos y su vagina con palos, su cuerpo. Y la xxx íntegra, digna. Y la abrazo, y me dijo "no me abrací [sic] tan fuerte porque todo me duele", pero siempre digna, me dijo. Y vamos a seguir a la lucha. (Entrevista 6, comunicación personal, 19 de noviembre de 2016)

La resistencia se articula desde lo afectivo, se articula desde la conciencia que el enfrentamiento contra quienes ejercen el poder coercitivo tiene consecuencias que son inscritas en los cuerpos de quienes accionan y resisten. A pesar de los abusos la comunidad resiste, pues la conciencia colectiva está orientada a un solo fin: sacar a la empresa del territorio, ello hace que cada uno 
de los episodios de enfrentamiento, incluso aquellos en los que se observa violencia extrema, sea un elemento que aviva la identidad colectiva y forja las relaciones íntimas y significativas de los actores que componen la acción. Al mismo tiempo, destaca el grado de unión y cohesión que tenía la acción, lo que no permitió que estas estrategias surtieran efecto, por el contrario, hizo que la acción tuviera un componente emotivo, épico, que entregaba sentido a la resistencia comunitaria.

La comunidad se enmarca en la exigencia de sus derechos, por encima de las consecuencias que esto pudiese implicar, transformándose en un actor político, que dentro del ser-estar juntos, del apropiarse del espacio, es capaz de politizar cada aspecto de la acción. De esta manera, se produce una oposición social objetivada por el espacio. El desierto tiene vida, es un espacio digno de apropiación, está situado, habitado. Los cuerpos, animales o humanos que lo habitan tienen valor y significado. Por ello, la lucha por la dignidad es un elemento reiterativo en los discursos.

\section{La importancia de los espacios y territorios}

Uno de los temas que emerge es la importancia de los espacios como elemento de interacción social y política, en el cual se posicionan los actores. La resistencia se apropia de los espacios y les entrega un simbolismo para la acción colectiva desarrollada. El espacio apropiado, dotado de significación, es un elemento importante durante el desarrollo del conflicto.

Uno de los espacios mencionados en las entrevistas es el conocido como "Pachamama", el cual es valorado como importante dentro del conflicto, pues en él se reunían las familias movilizadas y en el cual, los y las participantes interactuaban en una zona en la que confluían personas de todas las edades, generándose rutinas e interacciones que marcan el desarrollo de este conflicto. Se realza como un espacio social, por el significado que los y las participantes le dan, expresándose desde lo afectivo, relacional y político lo que se corrobora en los murales que se plasmaron posterior al término del conflicto.

Otro espacio es la plaza de Freirina, lugar que adquiere importancia debido a que se realizan en ella asambleas multitudinarias, ya que las sedes sociales no daban abasto para la cantidad de personas que asistían.

Pachamama y la plaza de la comuna fueron espacios en los que se desarrollaron diferentes actividades que construyeron elementos identitarios de la acción colectiva, es decir, los y las sujetas se reconocen como parte de esos espacios, le entregan significados, los simbolizan y se apropian; lo que potencia la construcción de identidad colectiva, la cual se desarrolla a lo largo de todo el proceso y que conlleva a sentirse parte del espacio, sentir que el mismo es parte de su cuerpo y comunidad. 
Acción colectiva, antagonismos y resistencia comunitaria en el conflicto socio-territorial de Freirina

Por otra parte, se visualiza la usurpación del espacio social que realiza la empresa, esta tiene una visión territorial distinta, la cual es visualizada por los y las entrevistadas como una mirada foránea que solo considera al territorio como terrenos baldíos, sin vida y sin actividad de la población, territorios desérticos, despolitizados, sacrificados.

[...] la empresa compró todos esos terrenos, entonces la cultura local se tuvo que transformar o modificar porque ellos usurparon territorio. Claramente cuando ellos compraron, ellos no nos fueron a decir "oye yo quiero este terreno" sino que compraron hectáreas y hectáreas sin darse cuenta qué es lo que estaban comprando; y claramente a la gente le molestó cuando vieron cercos y restricción del paso a lugares que ellos siempre, por años, ellos habían ido [...]. (Entrevista 3, comunicación personal, 19 de noviembre de 2016)

La ocupación y usurpación de los espacios por parte de la empresa es percibido como restricciones a la libertad y la vida cotidiana, ya que afectó las costumbres y tradiciones que históricamente había desarrollado la comunidad. Lo anterior es visto como una depredación, puesto que se barre con la flora y fauna local, los recursos naturales, los territorios ancestrales y el tejido social.

[...] entonces como no digo yo, cómo no pensar que esta empresa es una empresa depredadora, es una empresa que arrasó con todo, imagínate desierto florido donde todos sabemos las flores preciosas que se dan en ese lugar. Todo eso arrasó. Y sabes tú cómo pasaban las máquinas y arrastraba. Sabí [sic] que nosotros fuimos una vez a las visitas cuando iba la máquina (...) Sabes tú que la gente lloraba, porque ahí se iba todo pu, semillas, eh papas, lo que fuesen [...]. (Entrevista 2, comunicación personal, 19 de noviembre de 2016)

La intervención estatal mediante la represión es un punto de inflexión en el conflicto, dado que aviva la resistencia, radicaliza los repertorios de acción y genera batallas entre pobladores y fuerzas especiales. Es ahí donde el espacio toma relevancia, y se identifican lugares transcendentales en el desarrollo del conflicto. Ejemplo de ello es lo sucedido en lo que es denominado como "Batalla de Tatara", hito que se levanta como la primera instancia de radicalización de los repertorios de acción, en el cual la Asamblea Freirina decide tomar la carretera, lo que provoca el envío de fuerzas de orden público. Este lugar es identificado como estratégico, debido a que los y las participantes mantienen un conocimiento profundo de su territorio, el cual los favorece al momento del enfrentamiento. A la vez, se denota la 
importancia simbólica que tiene dicho lugar para los participantes, y la significancia de este para cada uno de ellos, demostrado al darle la connotación de Batalla. Otro punto es el bypass debido a la relevancia que el mismo mantiene; primero, por ser un lugar que conecta la ruta C-46 desde Vallenar hasta Huasco, por lo que tomarse ese punto específico tendría un impacto en el transporte, economía, y en la vía principal de la zona; y por otro, también mantiene un significado más potente, en relación a que el mismo es un símbolo de la instalación de Agrosuper en Freirina. El Bypass permitía un enlace más rápido entre las diferentes secciones de la empresa, una vez que la misma llega a instalarse en la comunidad, irrumpiendo paso directo a la ruta C-46. Esta acción es considerada como un ataque directo contra la empresa, una demostración de repudio contra la misma. La acción en ambos lugares implicó una gran represión, por lo que también contribuye a la memoria triunfal del conflicto.

Si bien, el territorio puede ser comprendido como aquella instancia en que se establecen las relaciones de poder, es también el espacio en el que se producen las relaciones sociales. En el caso de Freirina, la territorialidad se construye a partir de la memoria, es ahí donde tiene sentido y razón. La articulación de la acción colectiva con la memoria es rescatada en la forma que los habitantes asumen el territorio y su simbolismo.

[...] entonces yo te digo esos lugares, esas historias, la gente no permitió que se las quitara. ¿Qué hizo Agrosuper? No se preocupen, nosotros les vamos a dejar Piedras Grandes para que ustedes sigan haciendo sus tradiciones ¿Qué hizo la gente? No queremos limosnas, eso es nuestro y nadie nos va a quitar (...). (Entrevista 6, comunicación personal, 19 de noviembre de 2016)

El actor colectivo se define en función a la pertenencia a su territorio, en las características que forjan su identidad. Los pobladores y pobladoras le entregan una connotación simbólica y emocional, es parte de ellos y ellas, son cuerpo y territorio, un solo ser.

\section{Repertorios de la acción y resistencia}

Entre noviembre de 2011 a diciembre del 2012 los repertorios de acción tuvieron diversos fines. Es aquí donde encontramos marchas, velatones, cacerolazos, embanderamientos de casas y un plebiscito ciudadano. Las manifestaciones buscaron potenciar la fuerza de la acción colectiva, mostrando la importancia de mantenerse unidos, y que todos pudiesen manifestar su sentir de diversas maneras según las posibilidades de cada habitante.

La radio profeta, las 24 horas estábamos al tanto, porque de repente nosotros íbamos a descansar y con la radio pendiente; y lo otro que eran las campanas de la iglesia, la campana de la iglesia 
Acción colectiva, antagonismos y resistencia comunitaria en el conflicto socio-territorial de Freirina

y la bocina de los vehículos era lo que nosotros teníamos como la advertencia de que hay que salir y estamos en peligro y así nos organizamos (...) (Entrevista 6, comunicación personal, 19 de noviembre de 2016)

La resistencia se vincula a los elementos cotidianos que marcan el desarrollo de la comunidad. La radio, el repicar de la campana de la iglesia asoman como prácticas cotidianas de resistencia que son organizadas por los pobladores y pobladoras para articular la acción. Estos permiten comunicar y expresar las exigencias de la asamblea, les hace visibles, congrega a los medios de comunicación y acciona a la población a través de la irrupción del orden público. Son acciones aprendidas que, en el contexto de la lucha, adquieren un simbolismo y un significado atingente a la acción que se desarrolla.

[...] primero fueron con marchas, eh cacerolazos, después eh con reuniones, eh mesas de trabajo ¿Cachai? Con autoridades y con la empresa y, y ya al ver que, que la cuestión no tenía eh respuestas claras, nosotros empezamos a ser un poco más radicales ¿Cachai? Eh, nos fuimos a, a tomas de carreteras (...) fue de a poco primero y después se llegó a lo más extremo. (Entrevista 7, comunicación personal, 24 de octubre de 2016)

El abandono estatal y la indefensión generan la radicalización de los repertorios. El guión de acciones acude a elementos de la memoria colectiva para organizar la lucha y generar una identidad comunitaria organizada en defensa del territorio.

\section{Discusión}

El análisis de la acción colectiva organizada en Freirina nos permite comprender y visibilizar elementos ausentes en las discusiones y teorizaciones sobre la acción colectiva y los movimientos sociales. Nos llevó un tiempo comprender que los marcos analíticos que presentan estos postulados teóricos tienen sesgos patriarcales que sustentan las acciones en un entramado que niega u olvida los aspectos emotivos y afectivos de la acción comunitaria. Los discursos de los pobladores y pobladoras son elocuentes al remembrar el conflicto. Sus relatos, pero también su gestualidad, evocan con emoción cada una de las prácticas de resistencia, las formas de organización, la asamblea y cada uno de los aspectos que enmarcaron la movilización. De hecho, no es la instalación de la empresa la que origina la reacción comunitaria, la población se re-organiza cuando percibe/siente malos olores. A esa afectación se le da un significado y es esa la chispa que impulsa la acción. La afección, como acto político, inunda el relato de las personas que participan de la investigación, son esos sentires cotidianos los que se politizan y generan sentido. 
El orden social se inscribe en los cuerpos (Bourdieu, 1999), en cuerpos sintientes que son territorios-cuerpos articulados con los territorios-tierra (Paredes, 2008), así lo hacen ver los pobladores y pobladoras entrevistadas, se sienten frontera entre el desierto y la fertilidad. Es ahí cuando la acción tiene un motivo y un fin, cuidar la vida, conformar un ser-estar juntos que posibilite una resistencia comunitaria enmarcada en la defensa y protección de la vida. La comunidad articula una resistencia que es corporal, en los enfrentamientos con fuerzas especiales, pero también en la defensa y protección de los espacios y territorios.

La empresa tranza, compra, sin considerar corporalidades, sensaciones, vivencias. Negocia con los pobladores como si sus vidas fueran un producto tranzable. La asimetría de poder se instala, pues no se les visualiza como ente poseedor del poder de la palabra negociadora, del diálogo, por el contrario, se intenta generar una negociación ante la cual se resiste, resistencia que se articula en una ética del cuidado como mecanismo de resistencia en las acciones colectivas (Bolados et al., 2017). La resistencia través del cuidado de la otra y el otro es una confrontación al sistema mismo, orientada a desnaturalizar los sistemas de dominación y opresión presentes en las lógicas extractivistas y empresariales. Así, en el conflicto se identifican mecanismos asociados a las visiones clásicas de la acción colectiva como la identidad desplegada en forma colectiva, pero también, aspectos estructurales como el aprovechamiento por parte de la asamblea de las oportunidades políticas presentes y las estructuras de poder; así como también elementos relacionados con mecanismos emocionales que subyacen a la acción.

La acción colectiva que aquí se revisa es crítica, reflexiva, contenciosa y multidimensional, pues representa un férreo posicionamiento en términos culturales, sociales, políticos y económicos hacia las formas hegemónicas de comprender los espacios, territorios, cuerpos y emociones. Lo que se cuestiona desde la acción colectiva, es la idea de desarrollo, aquella vieja idea de que el crecimiento económico generará beneficios sociales, idea que está en la base de las formas tradicionales de extractivismo (Gudynas, 2011), en este sentido, se espera o aceptan sacrificios "locales" como necesarios para el bienestar "general” (p. 388). Sin embargo, las comunidades gestan resistencias dando valor al territorio-cuerpo que ha sido invisibilizado, convirtiéndoles en zona de sacrificio, espacio en el que la vida se convierte en un elemento superfluo, por ello se sitúan como protectores de esa vida, son la frontera entre la fertilidad y el desierto. Así, la defensa del medioambiente y las comunidades, dependen exclusivamente de grupos y comunidades que toman conciencia de los problemas y abusos que acarrean los grandes proyectos transnacionales y que estas generen acciones para combatir mediante sus recursos y organización los problemas principalmente asociados a contaminación y depredación de sus recursos naturales, tal como ha acontecido en la comunidad freirinense. 
Acción colectiva, antagonismos y resistencia comunitaria en el conflicto socio-territorial de Freirina

\section{Posibles conclusiones}

En el desarrollo del artículo se ha expuesto las formas en que se desarrolló el conflicto socioterritorial en Freirina, detallando las formas de acción colectiva, resistencia comunitaria, los antagonismos, la importancia de los espacios y territorios locales. Es importante destacar la organización comunitaria desplegada la que articula una acción colectiva contenciosa centrada en el conflicto, tal y como se observa en otros casos latinoamericanos, lo que da cuenta de las tensiones entre capitalismo y apropiación de la naturaleza, a través del despojo de los territorios y la precarización de la vida.

El caso de estudio permite reflexionar sobre la acción colectiva como respuesta comunitaria de sectores subalternizados ante la acción neoextractivista y estrategia de politización de los conflictos sociales para su resolución. Esto último es importante, pues solo a través de la resistencia comunitaria, comunidades como Freirina se configuran como un actor político visible en el contexto nacional, permitiendo con ello superar las asimetrías de poder, apropiándose de un discurso que subraya la necesidad de recuperación de la dignidad arrebatada por actores ajenos al territorio, y que revitaliza prácticas comunitarias, memorias, sentires y discursos propios.

\section{Referencias}

Arce, M. (2015). La extracción de recursos naturales y la protesta social en el Perú. Lima, Perú: Fondo Editorial de la Pontificia Universidad Católica del Perú.

Arriagada, E. (2012). El conflicto de polimetales en Arica. Movilización social, desarticulación local e intervención centralizada. En G. Delamaza., N. Cunill. y A. Joignant. (Ed), Nueva agenda de descentralización en Chile (pp. 459-485). Sentando más actores a la mesa. Santiago, Chile: RIL Editores / Universidad de Los Lagos.

Astudillo, F. (2015). Un Río Fantasma: Espacio, Regionalidad y Olvido en el Valle de Copiapó (tesis de maestría). Flacso, Buenos Aires, Argentina. Recuperado de https://repositorio. flacsoandes.edu.ec/bitstream/10469/8536/4/TFLACSO-2015FSCAP.pdf.

Bebbington, A. (2007). Minería, movimientos sociales y respuestas campesinas. Una ecología política de transformaciones territoriales. Lima, Perú: IEP/Cepes.

Bolados, P. (2016). Conflictos socio-ambientales/territoriales y el surgimiento de identidades post neoliberales (Valparaíso-Chile). Izquierdas, 31, 102-129.

Bolados, P., Cuevas, A., Alonso, K., Orellana, C., Castillo, A. y Damann, M. (2017). Ecofeminizar el territorio. La ética del cuidado como estrategia frente a la violencia extractivista entre las Mujeres de Zonas de Sacrificio en Resistencia (Zona Central, 
Chile). Ecología Política, 81-86.

Bourdieu, P. (1999). Intelectuales, politica y poder. Buenos Aires, Argentina: Eudeba. Delamaza, G. (2019). Consecuencias políticas de los conflictos socio-territoriales. Hacia una conceptualización pertinente. Revista Austral de Ciencias Sociales, (37), 139-160.

Duarte, C. y García-Carmona, A. (2013). Derechos humanos en la región de Atacama: migraciones y medio ambiente. Revista de Trabajo Social, (84), 19-30.

Durán, C. (2016). Acción colectiva y movimientos sociales: Disputas conceptuales y casos de estudio recientes. Izquierdas, (31), 286-90.

Eyerman, R. \& Jamison, A. (1991). Social movements: a cognitive approach. Cambridge: Polity Press.

García, A. (2012). Movimientos sociales y conflictos socio ecológicos en Atacama. Tensões Mundiais, 8(15), 213-232.

García, A. (2017). Gubernamentalidad y agua: analíticas del poder en el desierto de atacama. Civilizar Ciencias Sociales y Humanas, 17(33), 113-34.

Gudynas, E. (2011). El desarrollo en cuestión. Reflexiones desde América Latina. La Paz, Bolivia: Oxfam y CIDES UMSA.

Guerra, D. y Skewes, J. (2010). Acumulación por desposesión, respuestas locales en el remodelaje de los paisajes estuariales del sur de Chile. Chungará (Arica), 42(2), 451 463. doi: https://dx.doi.org/10.4067/S0717-73562010000200008.

Haesbaert, R. (2011). El mito de la desterritorialización. Del fin de los territorios a la multiterritorialidad. México: Siglo XXI.

Harvey, D. (2004). El Nuevo Imperialismo. Madrid, España: Akal Ediciones.

Instituto Nacional de Derechos Humanos. (2015). Mapa de conflictos socioambientales en Chile. Santiago, Chile: INDH.

Jasper, J. (2012). ¿De la estructura a la acción? La teoría de los movimientos sociales después de los grandes paradigmas. Sociológica (México), 27 (75), 7-48.

Jeréz, B. (2015). Conflictos ecoterritoriales, megaproyectos de minería y centrales hidroeléctricas en los andes patagónicos: Escenarios y desafíos emergentes para el trabajo social. Intervención Social, 4, 1-8.

Laval, C. y Dardot, P. (2015). Común. Ensayo sobre la revolución en el siglo XXI. Barcelona, España: Gedisa.

Maffesoli, M. (1990). El tiempo de las tribus. Barcelona, España: Icaria. 
Acción colectiva, antagonismos y resistencia comunitaria en el conflicto socio-territorial de Freirina

Maffesoli, M. (2012). El ritmo de la vida: variaciones sobre el imaginario posmoderno. México, D. F., México: Siglo XXI Editores.

Melucci, A. (1999). Acción colectiva, vida cotidiana y democracia. Ciudad de México, México: El Colegio de México.

Mora, A., Duarte, C. y Rodríguez, V. (2017). Conflicto socioterritorial por la instalación de la termoeléctrica Castilla en la Región de Atacama. Aprendizajes y desafíos para la intervención en trabajo social. Cuaderno de trabajo social, 10(1), 18-43.

Peña, L. (2014). Acciones colectivas contenciosas, proceso político y seguridad urbana. Construyendo geografías de la esperanza. Territorios, (31), 57-83. Doi: dx.doi. org/10.12804/territ31.2014.03.

Paredes, J. (2008). Hilando fino: Desde el feminismo comunitario. La Paz, Bolivia: CEDEC.

Reyes, S. y Rodríguez, J. (2015). Proyecto Hidroaysén: capitalismo extractivista, regulación estatal y acción colectiva en la Patagonia. Polis (Santiago), 14(40), 439-467. https:// dx.doi.org/10.4067/S0718-65682015000100021.

Rodríguez,V., Duarte, C. y Mora, A. (2015). Voces de mujeres y trabajo agrícola de temporada en el valle de Copiapó (2014-2015). Pilquen-Sección Ciencias Sociales, 18 (2), 3.

Svampa, M. (2011). Modelos de desarrollo, cuestión ambiental y giro eco-territorial. En H. Alimonda. (Coord), La naturaleza Colonizada (pp.182-215). Buenos Aires, Argentina: Ediciones CICCUS-CLACSO.

Tarrow, S. (2004). El poder en movimiento. Los movimientos sociales, la acción colectiva y la política. Madrid, España: Alianza editorial, S.A.

Tilly, C. (1978). From Mobilization to Revolution. Michigan: Addison-Wesley Publishing Company, Reading, Mass.

Touraine, A. (1984). El retorno del actor. Buenos Aires, Argentina: Ed. Sudamérica.

Vargas, F. (2014). El valle del Huasco, territorio dinámico entre la resistencia y el sacrificio. Análisis de la resistencia ciudadana frente a la planta faenadora de agrosuper en Freirina (tesis de maestría). Universidad de Chile, Santiago de Chile, Chile. 